\title{
Kondisi dan Potensi Dampak Pemanfaatan Air Tanah di Kabupaten Sumenep
}

\author{
Hendra Wahyudi \\ Staf pengajar Program Studi Diploma Teknik Sipil FTSP ITS
}

\begin{abstract}
ABSTRAK
Kabupaten Sumenep adalah Kabupaten yang terletak paling Timur yang ada di Pulau Madura merupakan Kabupaten penghasil minyak bumi sehingga anggaran untuk pembangunannya relative lebih tinggi dibandingkan dengan tiga kabupaten yang ada di Pulau Madura. Kemajuan pesat yang dicapai Kabupaten Sumenep perlu didukung oleh sumber daya air yang sangat memadai oleh sebab itu Pemerintah melalui Proyek Pengembangan Air Tanah J awa Timur telah lama mengembangkan potensi air tanah di Kabupaten Sumenep dengan membuat sumur sumur dalam untuk mengatasi kekeringan dan kekurangan air irigasi.Agar pemanfaatan air tanah tersebut tidak berlebihan sehingga dapat merusak lingkungan (intrusi air laut ) maka perlu dilakukan penelitian untuk melihat potensi air tanah dan dampak pemanfaatan air tanah di kabupaten Sumenep sehingga dapat dikembangkan guna mendukung kebutuhan air dipulau Madura yang akan semakin meningkat. Hasil Penelitian ini menunjukkan bahwa pemanfaatan air tanah yang terdapat di Kabupaten Sumenep sebesar 201.598,21 m3/hr Sedangkan potensi air tanah yang mungkin dapat dikembangkan diKabupaten Sumenep meliputi Cekungan Ambunten mencapai 60.690 $\mathrm{m} 3 /$ hari atau $22.151 .000 \mathrm{~m} 3 /$ tahun, besarnya recharge $166.030 \mathrm{~m} 3 /$ hari atau $60.600 .000 \mathrm{~m} 3 /$ tahun. Cekungan Sumenep mencapai $150.550 \mathrm{~m} 3 /$ hari atau $54.950 .000 \mathrm{~m} 3 /$ tahun, besarnya recharge $281.360 \mathrm{~m} 3 /$ hari atau 102.690 .000 $\mathrm{m} 3$ / tahun. Cekungan Toranggo mencapai $13.060 \mathrm{m3} /$ hari atau $4.766 .000 \mathrm{m3} /$ tahun, besarnya recharge $50.210 \mathrm{~m} 3 /$ hari atau $19.016 .000 \mathrm{~m} 3 /$ tahun tanpa mengakibatkan intrusi air laut dan letak pengembangan sumur agar tidak menyebabkan intrusi sejarak 2 kilometer dari garis pantai.
\end{abstract}

\section{PENDAHULUAN}

\section{$1.1 \quad$ Latar Belakang}

Kabupaten Sumenep adalah kabupaten yang posisinya diujung paling timur dari pulau Madura yang merupakan salah satu penghasil minyak dan gas bumi sehingga anggaran untuk pembangunannya relative lebih besar dibandingkan tiga kabupaten yang lain yang ada di Pulau Madura.

Kemajuan pesat yang dicapai Kabupaten Sumenep berkat mutiara hitam tersebut tentunya membutuhkan sumber daya air yang sangat memadai oleh sebab itu banyak upaya yang telah dilakukan antara lain dengan memanfaatkan air tanah dengan membuat sumur sumur baik dilakukan oleh penduduk maupun oleh Pemerintah melalui Proyek Pengembangan Air Tanah Jawa Timur.

Agar pemenfaatan sumber daya air tersebut dapat dilakukan secara optimal dan tidak menimbulkan kerusakan lingkungan ( intrusi air laut ) maka perlu dilakukan penelitian tentang potensi dan pemanfaatan air tanah dan dampaknya bagi Kabupaten Sumenep sehingga pengembangan potensi air tanah tersebut dapat lestari dilakukan secara aman.

Air kalau dilihat dari letaknya dapat dibagi menjadi dua yaitu air permukaan dan air tanah. Air permukaan jumlah dan keberadaannya akan dapat dilihat secara langsung dengan mata telanjang karena terletak dipermukaan sedangkan air tanah karena letaknya di dalam tanah maka jumlah dan potensinya perlu dilakukan pengamatan yang lebih teliti.

\subsection{Maksud dan Tujuan}

Maksud dan tuj uan penelitian ini adalah

- Untuk memperoleh gambaran tentang kondisi dan pemanfaatan air tanah saat ini di Kabupaten Sumenep. 
- Untuk memperoleh gambaran tentang kemungkinan pengembangan potensi air tanah dan dampak yang akan ditimbulkan.

- Untuk memberikan masukan bagi pengambil kebijakan tentang letak sumur pengembangan di Kabupaten Sumenep sehingga peningkatan pemanfaatan air tanah tidak menimbul kan intrusi air laut.

\subsection{Lokasi Kegiatan}

Lokasi kegiatan penelitian ini terletak di Kabupaten Sumenep dengan batas batas sebagai berikut :

- Batas sebelah Utara Laut J awa

- Batas sebelah Timur Laut J awa.

- Batas sebelah Selatan Selat Madura.

- Batas Sebelah Barat Kabupaten Pamekasan.

\section{KONDISI UMUM DAERAH PENELITIAN}

\subsection{Batas Administrasi}

Kabupaten Sumenep terletak pada posisi 40 55' - 70 24' Lintang Selatan dan 1130 32' 1150 15' Bujur Timur mempunyai luas areal kurang lebih sebesar $1156.08 \mathrm{~km} 2$ terdiri dari 17 kecamatan yaitu kecamatan Pragaan, Bluto, Saronggi, Kalianget, Sumenep, Lanteng, Ganding, Buluk Buluk, Pasongsongan, Ambunten, Rubaru, Dasuk, Manding, Batu Putih, Gapura, Batang batang, dan Dungkek.

\subsection{Topografi}

Topografi Kabupaten Sumenep terdiri dari dataran rendah yang membentang dipesisir Utara dan Selatan dengan ketinggian antara 0 - 50 meter d.p.l. dan dibagian tengah berupa perbukitan bergelombang dengan ketinggian 100 - 350 meter d.p.l.

\subsection{Tata Guna Lahan}

Tata guna lahan daerah Kabupaten Sumenep terbagi menjadi dua yaitu :

- Lahan Basah yang meliputi sawah, waduk Rawa dan tambak.
- Lahan Kering yang terdiri dari pemukiman, tegalan, Kebun, Hutan dan Lain lain

\subsection{Hidrologi}

Kabupaten Sumenep mempunyai iklim type Monsoon dengan dua musim yaitu hujan yang berlangsung antara bulan Nopember April dan Kemarau antara bulan Mei Oktober. Kondisi topografi, disamping angin Monsoon sangat mempengaruhi besarnya curah hujan, semakin tinggi letaknya di atas permukaan laut semakin besar pula curah hujannya bila dibandingkan dengan daerah dataran. Bagian tengah wilayah penelitian yang berupa perbukitan dan gunung, curah hujannya jauh lebih besar daripada curah hujan di dataran yang merupakan pantai, baik di bagian Utara maupun di bagian Selatan. Di daerah perbukitan curah hujan bahkan >2000 mm/th; yang memberikan kontribusi yang besar terhadap resapan air kedalam tanah, sedangkan di daerah pantai curah hujan berkisar antara 500 - 1000 $\mathrm{mm} /$ th.

Sedangkan kondisi klimatologi Kabupaten Sumenep adalah sebagai berikut :

\begin{tabular}{|l|c|c|c|}
\hline \multicolumn{1}{|c|}{ Uraian } & Minimum & Maksimum & Rata-rata \\
\hline Suhu $\left({ }^{\circ} \mathrm{C}\right)$ & 24 & 34 & 28 \\
\hline Penguapan (mm) & 94 & 204 & 150 \\
\hline Penyinaran Matahari (\%) & 40 & 100 & 76 \\
\hline Kelembapan (\%) & 60 & 90 & 80 \\
\hline Kecepatan Angin (Knots) & 13 & 22 & 16 \\
\hline
\end{tabular}

\section{LANDASAN TEORI}

Air tanah adalah air yang bergerak dalam lapisan tanah yang terdapat di dalam ruang ruang antara butir butir tanah yang membentuk itu atau dikenal dengan air lapisan dan di dalam retakan retakan dari batuan yang dikenal dengan air celah. Keadaan air tanah ada yang tekekang dan air tanah bebas.

Jika air tanah itu bebas maka permukaannya akan membentuk gradient yang dikenal dengan gradient hidrolik sehingga pergerakan air tanahnya akan membentuk sebuah kontur. 
Menurut hokum Darcy kecepatan aliran air tanah dapat dirumuskan sebagai berikut :

$V=k . ~ I$

Dimana :

$$
\begin{aligned}
\mathrm{V} & =\text { kecepatan aliran }(\mathrm{m} 3 / \mathrm{dt}) \\
\mathrm{K} & =\text { koefisien permeabilitas. } \\
\mathrm{I} & =\text { gradient hidrolik. }
\end{aligned}
$$

Pemanfaatan air tanah melalui sumur gali perhitungannya didasarkan pada kepadatan penduduk per kecamatan dengan asumsi bahwa air tanah yang diambil hanya dipergunakan untuk keperluan sehari-hari saja yaitu $60 \mathrm{l} / \mathrm{hr} / \mathrm{j}$ iwa.

Untuk memperkirakan kebutuhan dan penggunaan air tanah dangkal disetiap kecamatan, dipakai rumus sebagai berikut:

$\mathrm{Q}_{\mathrm{p}}=\mathrm{P}_{\mathrm{n}} \times \mathrm{K}_{\mathrm{p}}$

Dimana :

$\mathrm{Q}_{p}=$ penggunaan/kebutuhan air tanah dangkal $\left(\mathrm{I} / \mathrm{hr} / \mathrm{km}^{2}\right)$

$P_{n}=$ kepadatan penduduk rata-rata per kecamatan (jiwa/ $\mathrm{km}^{2}$ )

$\mathrm{K}_{\mathrm{p}}=$ kebutuhan air penduduk rata-rata (I/ hr/ jiwa)

Untuk menghitung Jumlah pengam bilan air tanah yang digunakan untuk mengairi areal irigasi dihitung dengan memakai rumus :

$\mathrm{Q}=\mathrm{t} \times \mathrm{Q}_{\mathrm{s}} \quad(\mathrm{I} / \mathrm{hr})$

Dimana :

$\mathrm{Q}=$ jumlah debit pemompaan $(\mathrm{I} / \mathrm{hr})$

$\mathrm{t}=\mathrm{jam}$ operasi pompa $(\mathrm{jam} / \mathrm{hr})$

$\mathrm{Q}_{\mathrm{s}}=$ kapasitas debit terpasang pompa (I/ det)

\section{METODOLOGI PENELITIAN}

Untuk melakukan penelitian dengan biaya dan yang efisien dan memperoleh hasil yang maksimal maka perlu disusun suatu metode pelaksanaannya yaitu :

- Inventarisasi data dan Orientasi lapangan. Tahapan berikutnya setelah persiapannya sudah mencapai progress seratus persen maka langkah selanjutnya adalah pengenalan medan dan inventarisasi data. Langkah ini dilakukan untuk melihat permasalahan yang ada dilapangan dan penelitian yang telah dilakukan sebelumnya sehingga tidak melakukan pengulangan tindakan.

- Analisa data. Tahapan ini adalah salah satu langkah yang akan dilakukan setelah semua data yang diperlukan untuk penelitian ini sudah diperoleh dan tahapan ini merupekan langkah awal agar variable yang diperlukan oleh program pendukung penelitian ini ( MUDFLOW ) dapat dijalankan.

- Pemodelan. Pada tahap ini yang dilakukan meliputi :

a. Penyiapan perangkat dan data input yang diperlukan oleh software Modflow

b. Kalibrasi kondisi steady - transient (elevasi muka air, debit pemompaan, dan kegaraman)

c. Kalibrasi kondisi unsteady

d. Peramalan berbagai skenario (dengan atau tanpa penambahan pemompaan serta dengan atau tanpa perubahan penggunaan Iahan).

- Analisa Hasil. Hasil yang dilakukan oleh program Mudflow masih berupa angka angka sehingga agar hasil tersebut dapat dibuat suatu kesimpulan maka perlu dilakukan analisa hasil.

\section{HASIL DAN PEMBAHASAN}

Kondisi Pemanfaatan air tanah di Kabupaten Sumenep adalah sebagai berikut :

\begin{tabular}{|c|l|r|}
\hline No & Kecamatan & Total $(\mathrm{m} 3 / \mathrm{hr})$ \\
\hline 1 & Pragaan & $20.969,39$ \\
\hline 2 & Bluto & $5.498,52$ \\
\hline 3 & Saronggi & $25.176,00$ \\
\hline 4 & Kalianget & $2.779,57$ \\
\hline 5 & Sumenep & $17.518,82$ \\
\hline 6 & Lenteng & $27.096,80$ \\
\hline 7 & Ganding & $3.638,35$ \\
\hline 8 & Bulukbuluk & $5.471,56$ \\
\hline 9 & Pasongsongan & $4.261,59$ \\
\hline 10 & Ambunten & $11.987,48$ \\
\hline 11 & Rubaru & $6.833,20$ \\
\hline 12 & Dasuk & $19.519,11$ \\
\hline 13 & Manding & $6.214,30$ \\
\hline 14 & Batuputih & $6.680,82$ \\
\hline 15 & Gapura & $27.974,30$ \\
\hline 16 & Batang-batang & $6.382,52$ \\
\hline 17 & Dungkek & $3.597,78$ \\
\hline Jumlah Total & $201.598,21$ \\
\hline
\end{tabular}


Hasil dan pembahasan simulasi yang dilakukan terhadap pengembangan air tanah di Kabupaten Sumenep dibagi menjadi tiga cekungan yaitu :

Cekungan Ambuten dengan berbagai debit pengambilan optimum atau yang mempunyai dampak terkecil terhadap kondisi air tanah nya yaitu dengan membuat sumur sebanyak 15 unit dengan berderet dari barat kearah timur dengan debit pengambilan maksimum $2700 \mathrm{m3} / \mathrm{hr}$ per sumur maka hasilnya dapat dilihat pada Gambar 1.

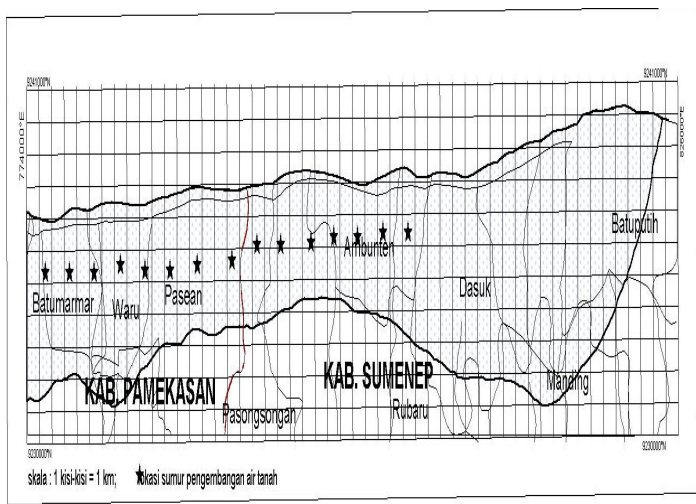

Gambar 1: Lokasi Sumur Pengembangan di Cekungan Ambunten.

Kondisi permukaan air tanah pada aquifer 1 pada tahun pengembangan pertama jika dilakukan pemompaan sebesar $2700 \mathrm{m3} / \mathrm{hr}$ dapat dilihat pada gambar 2 .

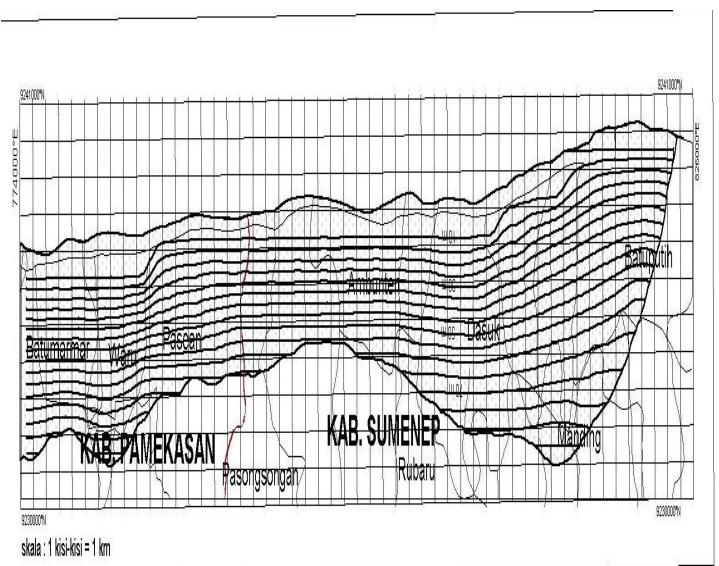

Gambar 2: Kondisi Transien Aquifer 1 pada tahun pertama
Kondisi permukaan air tanah pada aquifer 2 pada tahun pengembangan pertama jika dilakukan pemompaan sebesar $2700 \mathrm{m3} / \mathrm{hr}$ dapat dilihat pada gambar 3 .

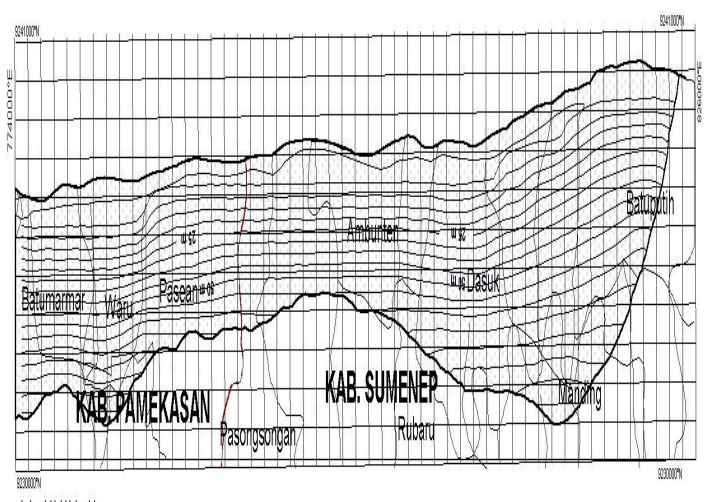

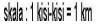

Gambar 3: Kondisi Transien Aquifer 2 pada tahun pertama.

Hasil neraca air tanah di cekungan Ambunten pada saat musim hujan dapat dilihat pada tabel 1 sebagai berikut :

Tabel 1: Neraca Air Tanah Cekungan Ambunten pada Saat Musim Hujan.

\begin{tabular}{|l|r|r|r|r|}
\hline & \multicolumn{2}{|c|}{ Akuifer 1 (dangkal) } & \multicolumn{2}{|c|}{ Akuifer 2 (dalam) } \\
\cline { 2 - 5 } & $\begin{array}{c}\text { Input } \\
\left(\mathrm{m}^{3} / \text { hari) }\right.\end{array}$ & $\begin{array}{c}\text { Output } \\
\left(\mathrm{m}^{3} / \text { hari) }\right.\end{array}$ & $\begin{array}{c}\text { Input } \\
\left(\mathrm{m}^{3} / \text { hari) }\right.\end{array}$ & $\begin{array}{c}\text { Output } \\
\left(\mathrm{m}^{3} / \text { hari) }\right.\end{array}$ \\
\hline Storage & 1152,8 & 5546,5 & 0,66792 & 3,6802 \\
Constant Head & 0 & 275830 & 0 & 5558 \\
Wells & 0 & 7069,9 & 0 & 57730 \\
Drains & 0 & 0 & 0 & 0 \\
Recharge & 116770 & 0 & 233810 & 0 \\
River Leakage & 0 & 0 & 0 & 0 \\
Head Dep & 0 & 0 & 0 & 0 \\
Zone 2 to 1 & 245.350 & 0 & 0 & 245.350 \\
Zone 1 to 2 & 0 & 74828 & 74828 & 0 \\
\hline Total & 363.280 & 363.280 & 308.640 & 308.640 \\
\hline
\end{tabular}

Hasil neraca air tanah di cekungan Ambunten pada saat musim kemarau dapat dilihat pada tabel 2 sebagai berikut : 
Tabel 2: Neraca Air Tanah di Cekungan Ambunten pada Saat Musim Kemarau

\begin{tabular}{|l|r|r|r|r|}
\hline & \multicolumn{2}{|c|}{ Akuifer 1 (dangkal) } & \multicolumn{2}{c|}{ Akuifer 2 (dalam) } \\
\cline { 2 - 5 } & $\begin{array}{c}\text { Input } \\
\left(\mathrm{m}^{3} / \text { hari }\right)\end{array}$ & $\begin{array}{c}\text { Output } \\
\left(\mathrm{m}^{3} / \text { hari) }\right.\end{array}$ & $\begin{array}{c}\text { Input } \\
\left(\mathrm{m}^{3} / \text { hari }\right)\end{array}$ & $\begin{array}{c}\text { Output } \\
\left(\mathrm{m}^{3} / \text { hari }\right)\end{array}$ \\
\hline Storage & 9567 & 0 & 6,1331 & 0,00012 \\
Constant Head & 0 & 243070 & 0 & 2137,9 \\
Wells & 0 & 7069 & 0 & 34370 \\
Drains & 0 & 0 & 0 & 0 \\
Recharge & 9124,2 & 0 & 0 & 0 \\
River Leakage & 0 & 0 & 0 & 0 \\
Head Dep & 0 & 0 & 0 & 0 \\
Zone 2 to 1 & 247.720 & 0 & 0 & 247.720 \\
Zone 1 to 2 & 0 & 16267 & 16267 & 0 \\
\hline Total & 266.410 & 266.410 & 305.520 & 305.520 \\
\hline
\end{tabular}

Pada akhir tahun pertama simulasi pengembangan sumur bor total input pada akuifer 1 sebesar $405.670 \mathrm{~m}^{3} /$ hari, besarnya recharge $166.030 \mathrm{~m}^{3} /$ hari, pengambilan air tanah $7069.9 \mathrm{~m}^{3} /$ hari. Pada akuifer 2 total input sebesar $307.680 \mathrm{~m}^{3} /$ hari, jumlah pengambilan air tanah $57.730 \mathrm{~m}^{3} /$ hari.

Pada akhir tahun kelima (2014) simulasi pengembangan sumur bor total input pada akuifer 1 sebesar $333.320 \mathrm{~m}^{3}$ / hari, besarnya recharge $166.030 \mathrm{~m}^{3} /$ hari, pengambilan air tanah $7069.9 \mathrm{~m}^{3} /$ hari. Pada akuifer 2 total input sebesar $306.060 \mathrm{~m}^{3} /$ hari, jumlah pengambilan air tanah $57.730 \mathrm{~m}^{3} /$ hari.

Cekungan Sumenep dengan berbagai debit pengambilan optimum atau yang mempunyai dampak terkecil terhadap kondisi air tanah nya yaitu dengan membuat sumur sebanyak 25 unit dengan berderet dari barat kearah timur dengan debit pengambilan maksimum $2700 \mathrm{m3} / \mathrm{hr}$ per sumur maka hasilnya dapat dilihat pada Gambar 4.

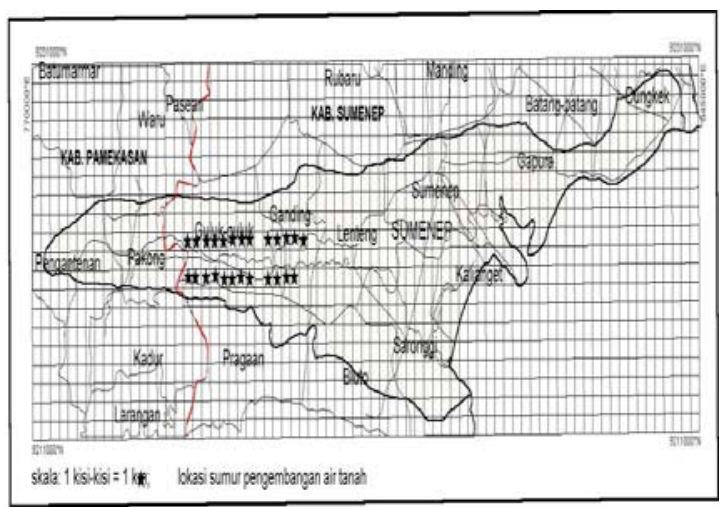

Gambar 4: Lokasi Sumur Pengembangan di Cekungan Sumenep.

Kondisi permukaan air tanah pada aquifer 1 pada tahun pengembangan pertama jika dilakukan pemompaan sebesar $2700 \mathrm{~m} 3 / \mathrm{hr}$ dapat dilihat pada gambar 5 .

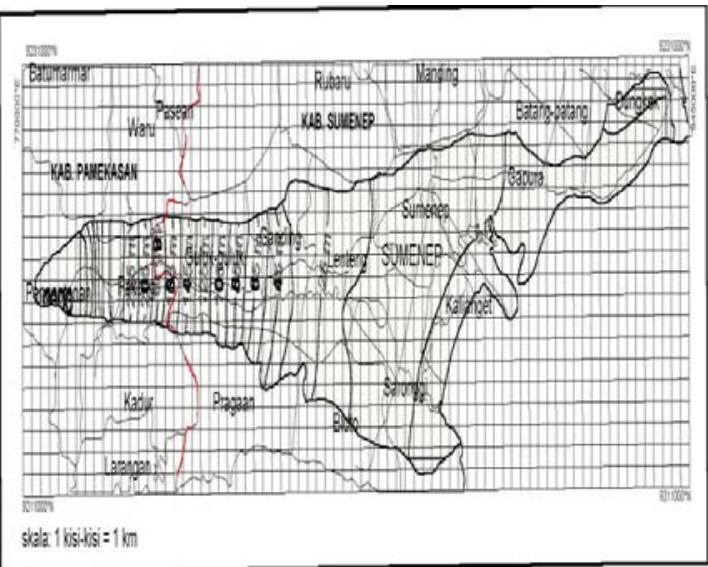

Gambar 5: Kondisi Transien Aquifer 1 pada tahun pertama

Kondisi permukaan air tanah pada aquifer 2 pada tahun pengembangan pertama jika dilakukan pemompaan sebesar $2700 \mathrm{m3} / \mathrm{hr}$ dapat dilihat pada gambar 6 .

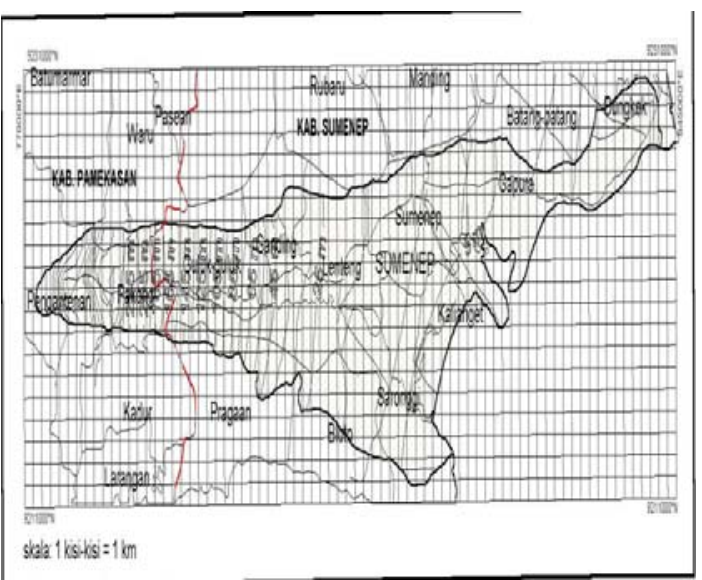

Gambar 6: Kondisi Transien Aquifer 2 pada Tahun Pertama. 
Hasil neraca air tanah di cekungan Sumenep pada saat musim hujan dapat dilihat pada tabel 3. sebagai berikut :

Tabel 3: Neraca Air Tanah Cekungan Sumenep pada Saat Musim Hujan.

\begin{tabular}{|l|r|r|r|r|}
\hline & \multicolumn{2}{|c|}{ Akuifer 1 (dangkal) } & \multicolumn{2}{c|}{ Akuifer 2 (dalam) } \\
\cline { 2 - 5 } & $\begin{array}{c}\text { Input } \\
\left(\mathrm{m}^{3} / \text { hari }\right)\end{array}$ & $\begin{array}{c}\text { Output } \\
\left(\mathrm{m}^{3} / \text { hari }\right)\end{array}$ & $\begin{array}{c}\text { Input } \\
\left(\mathrm{m}^{3} / \text { hari }\right)\end{array}$ & $\begin{array}{c}\text { Output } \\
\left(\mathrm{m}^{3} / \text { hari }\right)\end{array}$ \\
\hline Storage & 3928 & 0 & 2,3451 & 40,032 \\
Constant Head & 0 & 13505 & 80316 & 78879 \\
Wells & 0 & 8005,6 & 0 & 102690 \\
Drains & 0 & 0 & 0 & 0 \\
Recharge & 226.280 & 0 & 233810 & 0 \\
River Leakage & 0 & 0 & 0 & 0 \\
Head Dep & 0 & 0 & 0 & 0 \\
Zone 2 to 1 & 41.487 & 0 & 0 & 41.487 \\
Zone 1 to 2 & 0 & 142.780 & 142.780 & 0 \\
\hline Total & 271.700 & 271.700 & 223.100 & 223.100 \\
\hline
\end{tabular}

Hasil neraca air tanah di cekungan Sumenep pada saat musim kemarau dapat dilihat pada tabel 4 sebagai berikut :

Tabel 4: Neraca Air Tanah di Cekungan Sumenep pada Saat Musim Kemarau

\begin{tabular}{|l|r|r|r|r|}
\hline \multirow{2}{*}{} & \multicolumn{2}{|c|}{ Akuifer 1 (dangkal) } & \multicolumn{2}{c|}{ Akuifer 2 (dalam) } \\
\cline { 2 - 5 } & $\begin{array}{c}\text { Input } \\
\left.\text { ( } \mathrm{m}^{3} / \text { hari }\right)\end{array}$ & $\begin{array}{c}\text { Output } \\
\left(\mathrm{m}^{3} / \text { hari }\right)\end{array}$ & $\begin{array}{c}\text { Input } \\
\left(\mathrm{m}^{3} / \text { hari }\right)\end{array}$ & $\begin{array}{c}\text { Output } \\
\left(\mathrm{m}^{3} / \text { hari }\right)\end{array}$ \\
\hline Storage & 77346 & 0 & 45,704 & 0 \\
Constant Head & 654,8 & 13505 & 94553 & 48395 \\
Wells & 0 & 8005,6 & 0 & 102690 \\
Drains & 0 & 0 & 0 & 0 \\
Recharge & 0 & 0 & 0 & 0 \\
River Leakage & 0 & 0 & 0 & 0 \\
Head Dep & 0 & 0 & 0 & 0 \\
Zone 2 to 1 & 21096 & 0 & 0 & 21096 \\
Zone 1 to 2 & 0 & 77587 & 77587 & 0 \\
\hline Total & 99.097 & 99.097 & 172.190 & 172.190 \\
\hline
\end{tabular}

Pada akhir tahun pertama simulasi pengembangan sumur bor total input pada akuifer 1 sebesar $323.480 \mathrm{~m}^{3} /$ hari, besarnya recharge $281.360 \mathrm{~m}^{3} /$ hari, pengambilan air tanah $8005.6 \mathrm{~m}^{3} /$ hari. Pada akuifer 2 total input sebesar $213.630 \mathrm{~m}^{3} /$ hari, jumlah pengambilan air tanah $102.690 \mathrm{~m}^{3} /$ hari.

Pada akhir tahun kelima (2014) simulasi pengembangan sumur bor total input pada akuifer 1 sebesar $194.470 \mathrm{~m}^{3} /$ hari, besarnya recharge $144.870 \mathrm{~m}^{3} /$ hari, pengambilan air tanah $8005.6 \mathrm{~m}^{3} /$ hari. Pada akuifer 2 total input sebesar $21.280 \mathrm{~m}^{3} /$ hari, jumlah pengambilan air tanah $102.690 \mathrm{~m}^{3} /$ hari.

Cekungan Toranggo dengan berbagai debit pengambilan optimum atau yang mempunyai dampak terkecil terhadap kondisi air tanah nya yaitu dengan membuat sumur sebanyak 10 unit dengan berderet dari barat kearah timur dengan debit pengambilan maksimum $1000 \mathrm{~m} 3 / \mathrm{hr}$ per sumur maka hasilnya dapat dilihat pada Gambar 7

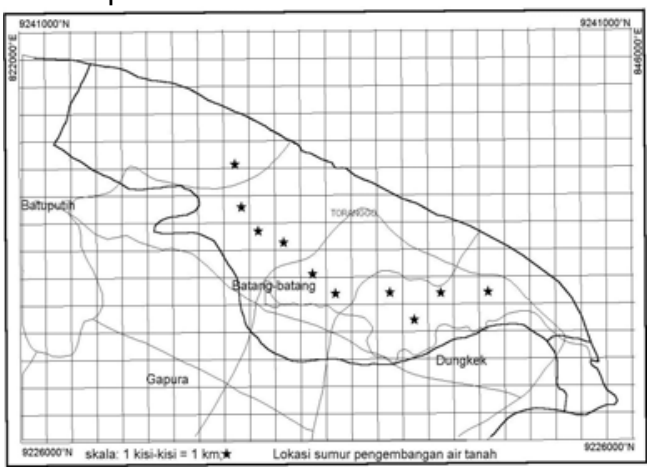

Gambar 7: Lokasi Sumur Pengembangan di Cekungan Toranggo.

Kondisi permukaan air tanah pada aquifer 1 pada tahun pengembangan pertama jika dilakukan pemompaan sebesar $2700 \mathrm{m3} / \mathrm{hr}$ dapat dilihat pada gambar 8 .

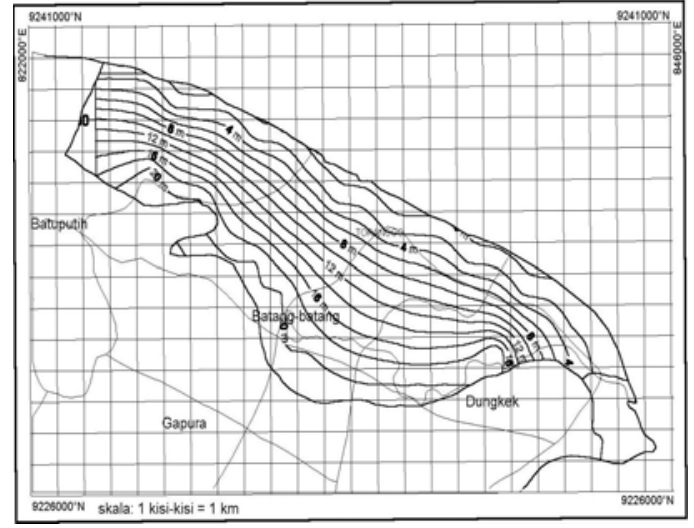

Gambar 5: Kondisi Transien Aquifer 1 pada tahun pertama

Kondisi permukaan air tanah pada aquifer 2 pada tahun pengembangan pertama jika dilakukan pemompaan sebesar $2700 \mathrm{m3} / \mathrm{hr}$ dapat dilihat pada gambar 9 . 


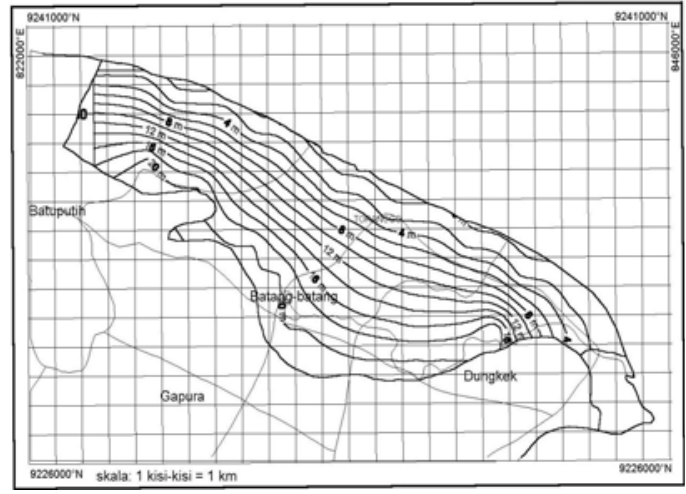

Gambar 9: Kondisi Transien Aquifer 2 pada tahun pertama.

Hasil neraca air tanah di cekungan Taranggo pada saat musim hujan dapat dilihat pada tabel 5 sebagai berikut:

Tabel 5: Neraca Air Tanah Cekungan Taranggo pada Saat Musim Hujan.

\begin{tabular}{|l|r|r|r|r|}
\hline \multirow{2}{*}{} & \multicolumn{2}{|c|}{ Akuifer 1 (dangkal) } & \multicolumn{2}{c|}{ Akuifer 2 (dalam) } \\
\cline { 2 - 5 } & Input (m3/hari) & $\begin{array}{c}\text { Output } \\
\text { (m/3/hari) }\end{array}$ & Input (m3/hari) & $\begin{array}{c}\text { Output } \\
\text { (m/hari) }\end{array}$ \\
\hline Storage & 40388 & 0,0063970 & 1,6374 & 0 \\
Constant Head & 0 & 98678 & 71597 & 4824,6 \\
Wells & 0 & 762,61 & 0 & 10237 \\
Drains & 0 & 0 & 0 & 0 \\
Recharge & 0 & 0 & 0 & 0 \\
River Leakage & 0 & 0 & 0 & 0 \\
Head Dep & 0 & 0 & 0 & 0 \\
Zone 2 to 1 & 82.372 & 0 & 0 & 82.372 \\
Zone 1 to 2 & 0 & 25836 & 25836 & 0 \\
\hline Total & 125.280 & 125.280 & 97.434 & 97.434 \\
\hline
\end{tabular}

Hasil neraca air tanah di cekungan Toranggo pada saat musim kemarau dapat dilihat pada tabel 6 sebagai berikut :
Tabel 6: Neraca Air Tanah di Cekungan Toranggo pada Saat Musim Kemarau

\begin{tabular}{|l|r|r|r|r|}
\hline & \multicolumn{2}{|c|}{ Akuifer 1 (dangkal) } & \multicolumn{2}{c|}{ Akuifer 2 (dalam) } \\
\cline { 2 - 5 } & $\begin{array}{c}\text { Input } \\
\left(\mathrm{m}^{3} / \text { hari }\right)\end{array}$ & $\begin{array}{c}\text { Output } \\
\left(\mathrm{m}^{3} / \text { hari) }\right.\end{array}$ & $\begin{array}{c}\text { Input } \\
\left(\mathrm{m}^{3} / \text { hari }\right)\end{array}$ & $\begin{array}{c}\text { Output } \\
\left(\mathrm{m}^{3} / \text { hari) }\right.\end{array}$ \\
\hline Storage & 162,91 & 0 & 0,1061 & 0 \\
Constant Head & 0 & 79433 & 90270 & 0 \\
Wells & 0 & 762,61 & 0 & 10.237 \\
Drains & 0 & 0 & 0 & 0 \\
Recharge & 0 & 0 & 0 & 0 \\
River Leakage & 0 & 0 & 0 & 0 \\
Head Dep & 0 & 0 & 0 & 0 \\
Zone 2 to 1 & 80.366 & 0 & 0 & 80.366 \\
Zone 1 to 2 & 0 & 333,92 & 333,92 & 0 \\
\hline Total & 80.529 & 80.529 & 90.604 & 90.604 \\
\hline
\end{tabular}

Pada akhir tahun pertama simulasi pengembangan sumur bor total input pada akuifer 1 sebesar $133050 \mathrm{~m}^{3} /$ hari, besarnya recharge $50.216 \mathrm{~m}^{3} /$ hari, pengambilan air tanah $762.61 \mathrm{~m}^{3} /$ hari. Pada akuifer 2 total input sebesar $99.395 \mathrm{~m}^{3} /$ hari, jumlah pengambilan air tanah $10.237 \mathrm{~m}^{3} /$ hari.

Pada akhir tahun kelima (2014) simulasi pengembangan sumur bor total input pada akuifer 1 sebesar $104.030 \mathrm{~m}^{3} /$ hari, besarnya recharge $25.646 \mathrm{~m}^{3} /$ hari, pengambilan air tanah $762.61 \mathrm{~m}^{3} /$ hari. Pada akuifer 2 total input sebesar $91.013 \mathrm{~m}^{3} /$ hari, jumlah pengambilan air tanah $10.237 \mathrm{~m}^{3} /$ hari.

\section{KESIMPULAN DAN SARAN}

\subsection{Kesimpulan}

Dari penelitian yang sudah dilakukan dapat diambil suatu kesimpulan sebagai berikut :

- Jumlah pemanfaatan air tanah di kabupaten Sumenep sebesar 201.598,21 $\mathrm{m} 3 / \mathrm{hr}$.

- Sistem akuifer Sumenep terdiri atas dua kelompok lapisan akuifer. Kelompok akuifer atas bersifat tidak tertekan tersusun oleh material yang halus, dengan kedalaman hingga sekitar 40 - 50 $\mathrm{m}$. Kelompok akuifer bawah umumnya bersifat tidak tertekan hingga semi tertekan tersusun oleh material batugamping yang berbutir kasar, dengan kedalaman sekitar $40-100 \mathrm{~m}$. Di beberapa tempat sistem akuifer 
tersusun oleh batugamping dari permukaan tanah sampai kedalaman sekitar $100 \mathrm{~m}$.

- Daerah dataran pantai utara sekitar Ambunten, morfologi pantainya pada jarak $2 \mathrm{~km}$ dari pantai ketinggian topografinya mencapai $100 \mathrm{~m}$. Di dataran pantai utara tersebut di bagian timur sekitar Ambunten yang pantainya curam debit aman 30 liter/detik/sumur pada jarak $2 \mathrm{~km}$ dari pantai. Di Toranggo debit aman di dataran pantai sekitar 11 liter/detik/sumur pada jarak $2 \mathrm{~km}$ dari pantai.

- Pemanfaatan air tanah di Cekungan Ambunten $60.690 \mathrm{~m}^{3} /$ hari atau $22.151 .000 \mathrm{~m}^{3} /$ tahun, besarnya recharge $166.030 \mathrm{~m}^{3} /$ hari atau 60.600 .000 $\mathrm{m}^{3} /$ tahun.

- Pemanfaatan air tanah di Cekungan Sumenep $150.550 \quad \mathrm{~m}^{3} /$ hari atau $54.950 .000 \mathrm{~m}^{3} /$ tahun, besarnya recharge $281.360 \mathrm{~m}^{3} /$ hari atau 102.690 .000 $\mathrm{m}^{3} /$ tahun.

- Pemanfaatan air tanah di Cekungan Toranggo $13.060 \mathrm{~m}^{3} /$ hari atau 4.766 .000 $\mathrm{m}^{3} /$ tahun, besarnya recharge 50.210 $\mathrm{m}^{3} /$ hari atau $19.016 .000 \mathrm{~m}^{3} /$ tahun.

\subsection{Saran}

Berdasarkan kondisi serta potensi dampak pemanfaatan air tanah di Kabupaten Sumenep maka untuk pengembangannya perlu kehati-hatian untuk daerah dataran dekat pantai. Jarak sumur bor ke garis pantai paling aman untuk menghindari intrusi air laut, sekitar $2 \mathrm{~km}$ dari garis pantai dengan debit pengambilan air tanah maksimum 10 liter/ detik.

Disarankan untuk membangun embung atau sumur resapan di daerah hulu atau perbukitan yang berfungsi untuk meresapkan air hujan yang jatuh ke permukaan tanah sehingga dapat menambah cadangan air tanah, selain juga untuk mengurangi resiko banjir di daerah hilir atau dataran pada saat terjadi hujan lebat di musim penghujan.

Perkembangan kondisi air tanah yang dapat diamati dari perubahan kedalaman muka air tanah perlu diukur dan dipantau secara berkala sehingga dapat diketahui kecende rungan perkembangan cadangan air tanah dan data pemantauan tersebut sangat berguna untuk perencanaan di waktu mendatang baik untuk pengembangan air tanah maupun untuk upaya pelestarian air tanah.

\section{DAFTAR ACUAN}

Anderson, M.D, and W.W. Woessner, 1992. Applied Ground Water Modelling. Simulation of Flow and Advective Transport.

Freeze. R.A. and Cherry. J. A, 1979. Groundwater, Prentice Hall, Inc, Englewood Cliff, New J ersey.

Kruseman. G.P. and De Ridder.N.A, 1990, Analysis And Evaluation of Pumping Test Data, International Institute For Land Reclamation And Improvement, Wageningen, The Netherlands

Nilson Guiger and Thomas Franz, User's Manual for Visual MODFLOW

Soekardi Puspowardoyo (1985). Peta Hidrogeologi Indonesia, Lembar VIII Surabaya, Skala $1: 250.000$, Direktorat Geologi Tata Lingkungan, Bandung.

Suyono Sosrodarsono Dan Kensa ku Takeda, 1976. Hidrologi Untuk Pengairan, PT. Pradnya Paramita, J akarta. 